\title{
(6) OPEN ACCESS \\ Direct-to-consumer genetic testing for predicting sports performance and talent identification: Consensus statement
}

\author{
Nick Webborn, ${ }^{1}$ Alun Williams, ${ }^{2}$ Mike McNamee, ${ }_{1}^{3}$ Claude Bouchard, ${ }^{4}$ \\ Yannis Pitsiladis, ${ }^{5}$ Ildus Ahmetov ${ }_{1}^{6}$ Euan Ashley, ${ }_{1}^{7}$ Nuala Byrne, ${ }^{8}$ Silvia Camporesi ${ }_{1}{ }^{9}$ \\ Malcolm Collins, ${ }^{10}$ Paul Dijkstra, ${ }^{11}$ Nir Eynon, ${ }^{12}$ Noriyuki Fuku, ${ }^{13}$ Fleur C Garton, ${ }^{14}$ \\ Nils Hoppe ${ }^{15}$ Søren Holm, ${ }^{16}$ Jane Kaye, ${ }^{17}$ Vassilis Klissouras, ${ }^{18}$ Alejandro Lucia, ${ }_{1}{ }^{19}$ \\ Kamiel Maase, ${ }^{20}$ Colin Moran, ${ }^{21}$ Kathryn N North, ${ }^{14}$ Fabio Pigozzi, ${ }^{22}$ Guan Wang ${ }^{5}$
}

- Additional material is published online only. To view please visit the journal online (http://dx.doi.org/10.1136/ bjsports-2015-095343).

For numbered affiliations see end of article.

\section{Correspondence to} Dr Alun Williams, MMU Sports Genomics Laboratory, Department of Exercise and Sport Science, Manchester Metropolitan University, Crewe Green Road, Crewe, CW1 5DU, UK

A.G.Williams@mmu.ac.uk

Accepted 25 September 2015

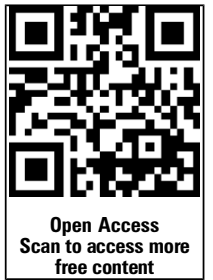

CrossMark

To cite: Webborn $\mathrm{N}$, Williams A, McNamee M, et al. Br I Sports Med 2015:49:1486-1491.

\section{ABSTRACT}

The general consensus among sport and exercise genetics researchers is that genetic tests have no role to play in talent identification or the individualised prescription of training to maximise performance. Despite the lack of evidence, recent years have witnessed the rise of an emerging market of direct-toconsumer marketing (DTC) tests that claim to be able to identify children's athletic talents. Targeted consumers include mainly coaches and parents. There is concern among the scientific community that the current level of knowledge is being misrepresented for commercial purposes. There remains a lack of universally accepted guidelines and legislation for DTC testing in relation to all forms of genetic testing and not just for talent identification. There is concern over the lack of clarity of information over which specific genes or variants are being tested and the almost universal lack of appropriate genetic counselling for the interpretation of the genetic data to consumers. Furthermore independent studies have identified issues relating to quality control by DTC laboratories with different results being reported from samples from the same individual. Consequently, in the current state of knowledge, no child or young athlete should be exposed to DTC genetic testing to define or alter training or for talent identification aimed at selecting gifted children or adolescents. Large scale collaborative projects, may help to develop a stronger scientific foundation on these issues in the future.

\section{INTRODUCTION-DIRECT-TO-CONSUMER MARKETING}

The general consensus among sport and exercise genetics researchers is that genetic tests, based on current knowledge, have no role to play in talent identification or the individualised prescription of training to maximise performance. Despite the lack of evidence, recent years have witnessed the rise of an emerging market of direct-to-consumer marketing (DTC) tests that claim to be able to identify children's athletic talents. Targeted consumers include mainly coaches and parents. Early talent identification is seen as a starting point to success and on the basis of the results of the genetic tests parents and coaches are led to believe that they can acquire knowledge to plan and invest in a child's future. It is vitally important that sport and exercise medicine practitioners are fully aware of the state of the evidence in relation to genetic testing and the limitations of current knowledge. This article reviews the issues around the currently available evidence behind the genetic testing, comments on the ethical considerations and makes recommendations about such tests.

\section{STATEMENT ON BACKGROUND TO THE CONSENSUS PROCESS}

A group of world experts in the field of genomics, exercise, sport performance, disease, injury and antidoping gathered with the International Federation of Sports Medicine (FIMS) Scientific Commission for a symposium to discuss the current state of knowledge and to share ideas. One key concern was the misuse of research evidence and the misinformation about genetic testing, particularly when marketed directly to the public, coaches or parents. This is known as DTC testing for the purpose of talent identification and to assess potential for future sports performance. There have been a variety of documents that have addressed issues for DTC Genetic Testing in relation to screening for disease, or to identifying genetic carriers, including those from the European Workshop on Genetic Testing Offer in Europe, the Human Genetics Commission (UK), American College of Medicine Genetics among others. ${ }^{1-3}$ However, these documents relate mainly to testing for disease states or heritability of conditions and no organisation has specifically addressed the issue in regard to the world of sport for talent identification.

The sports medicine community has a duty of care to protect the health and well-being of athletes based on the current scientific knowledge.

The consensus statement was developed across four areas:

1. Genetics-expert opinion of the scientific evidence in the field of genomics, exercise, sport performance from the participants of the Genomics, Genetics and Exercise Biology Symposium.

2. Sports medicine-consideration of the impact of DTC testing for young athletes and the need for education for sport and exercise medicine practitioners by the FIMS Scientific Commission.

3. Ethical and Legal-independent international expert review of this document. 
4. An internet review of DTC tests commercially available-In June 2015, internet searches were conducted from within the UK to identify commercially-available sport and exercise-related genetic tests for humans, a follow-up to a similar analysis conducted in June $2013 .^{4}$ As in previous reports, four English language internet search terms GENETIC, TEST, EXERCISE and SPORT were used in a simple search in two popular internet search engines (Google and Bing), as a potential consumer might do. In addition, other commercially available sport and exercise-related genetic tests, of which the authors were already aware, were included in the results. The websites of the commercial operations identified were explored manually and, if available, details about the numbers and identities of genetic variants being tested were identified. The recorded number of variants tested, and the names of the genes corresponding to the variants tested, required some subjective interpretation for their relevance to sport and exercise where this was not clear on the websites. For example, genetic tests marketed in relation to body composition phenotypes, but not clearly marketed as having a direct interaction with exercise, were not included. In addition, in some instances gene names but not specific variant details were identified, so some assumptions have been made regarding the precise variants being tested in those cases.

This statement does not relate to genetic testing for disease or specifically for cardiovascular conditions predisposing to sudden death related to exercise or sports performance.

\section{SANTORINI 2015 CONSENSUS QUESTIONS \\ What are the issues around DTC genetic testing?}

The science of genomics has advanced over the past decade at a rate unimagined by the medical scientific community. Not only is genetic testing becoming more commonplace in the clinical setting, but it has also reached the general public. Testing has also become much cheaper. From the $\$ 2.7$ billion it cost to sequence the first whole human genome, it now costs less than $\$ 1000$ and continues to fall. ${ }^{5}$ For analysis of specific variants this is even less, which is why companies can offer genetic testing to the public on a commercial basis. However, while the price of sequencing or genotyping has dramatically dropped, the interpretation of what the results mean is still at an early stage. ${ }^{6-10}$ Any genetic test should be evaluated against four main criteria: analytic validity, clinical validity, clinical utility and the associated ethical, legal and social implications. ${ }^{11}$

The pace of advance in sequencing and genotyping technology has far exceeded the pace of change in related regulation. Testing is poorly regulated with no worldwide agreement as illustrated by the following examples. Legislation currently varies from country to country in Europe. While France, Germany, Portugal and Switzerland have specific legislation that defines that genetic tests can only be carried out by a medical doctor, there is currently no regulation in the UK. ${ }^{12} \mathrm{~A}$ new draft European Union law is still under negotiation between member states. It would require companies to provide scientific evidence for claims, and restrict or ban sales of genetic tests directly to consumers. ${ }^{1}$ The In Vitro Diagnostics (IVD) Regulation passed first reading in the European Parliament in 2014 and is currently under negotiation at the Council, representing member states. ${ }^{13}$ This new law would require companies to provide evidence of the clinical validity of their genetic tests and would require medical supervision of testing. Australia has recently amended the Therapeutic Goods Act (July 2014) to regulate the supply and advertising of DTC genetic testing. This testing is prohibited in Australia, except where specifically approved by the Therapeutic Goods Administration (TGA), which includes proof that it is being performed in an accredited laboratory with sufficient clinical validity and utility. Companies can take tests to market without any independent analysis to verify their claims. In the USA, The Food and Drug Administration (FDA) has the authority to regulate genetic tests, but has only regulated the relatively small number of genetic tests sold to laboratories as kits. Although the FDA plans to expand its regulation to all genetic tests, this has not yet occurred. ${ }^{14} \mathrm{~A}$ report by USA Government Accountability Office (GAO) to the US Senate highlights the problem: ${ }^{15}$ "A genetic test is considered by the FDA to be a medical device only if it is manufactured as a freestanding 'kit' and sold to a laboratory. Presently, though, most genetic tests are not sold as kits but are manufactured in-house by clinical laboratories. In these cases, the laboratory itself decides whether a test has sufficient 'clinical validity' (ie, is sufficiently effective at measuring what it purports to measure). Although all clinical laboratories must be approved under the Clinical Laboratory Improvement Amendments of 1988 (CLIA) and meet general standards applicable to all laboratories, there is no genetic testing specialty under CLIA." The absence of monitored quality control at the laboratory is also an issue. In the GAO report, samples of DNA from the same people were sent under different names and to different laboratories yet different genetic variants were reported for the same individual. ${ }^{15}$

Of concern also to exercise and sport geneticists is that there are DTC health-related tests aimed at giving nutritional and lifestyle information based on a limited genetic analysis, sometimes called 'nutrigenetic' tests. In this case, the individual is often encouraged to purchase multivitamin and mineral products. The GAO report concluded that the "results encourage the purchase of supplements that are overpriced, make unproven medical claims, and may even be harmful". ${ }^{15}$

\section{What DTC tests are currently available?}

Thirty-nine companies were identified as providing DTC genetic tests that were marketed in relation to sport or exercise performance or injury. For 21 of the 39 companies (54\%), it was not possible to identify the specific DNA sequence variants tested. For the 18 companies that did present information about their genetic tests on their websites, the most commonly-tested variant was the ACTN3 R577X polymorphism that was tested by 16 of those 18 companies (89\%). The second most commonly-tested variant was the ACE I/D polymorphism that was tested by 11 of those 18 companies (61\%). The median number of variants tested by the 18 companies was 6 , ranging from 1 to 27 .

\section{Who are they aimed at, who can request them and what do they claim to show?}

DTC tests are aimed at individuals, coaches, parents, athletes and sports teams but indeed anyone who is prepared to pay for the test, and willing to send a saliva sample or buccal smear, can request a test. Since the sample collection process is simple it can be completed at home by any individual and mailed to a laboratory anywhere in the world. The claims of DTC websites in relation to sport performance and talent identification are numerous and concerning as they are largely without scientific foundation. Samples of these claims are shown in the box 1 below.

Since the last comparable survey of $\mathrm{DTC}^{4}$ the number of companies providing DTC genetic tests appears to have almost doubled from 22 identified in 2013 to 39 identified in 2015. Only 14 of the original 22 companies identified appear to still 
Box 1 Examples of claims from direct-to-consumer marketing websites

- Discover how your genes contribute to your athletic traits;

- Personalise your training based on your sports genetics results;

- Take advantage of your inherent strengths and overcome your limitations;

- Gives parents and coaches early information on their child's genetic predisposition for success in team or individual speed/power or endurance sports;

- Genetic predisposition determination can be valuable in outlining training and conditioning programmes necessary for athletic and sport development;

- Test results may be used later in development with other athletic performance;

- We use your DNA results to help you lose fat, get lean, build muscle, get fitter;

- Genetic test of athletic abilities describes:

- better or equal disposition to engage in either endurance sports or power sports;

- the score of genetic predisposition to engage in either endurance or power sports on 8-point scale;

- the regulation of blood supply, work capacity and metabolic processes in your muscles;

- the type of muscle fibres-fast-twitch or slow-twitch;

- the availability of energy in cells;

- the availability of constant energy supply in your muscles during exercise;

- the presence and extent of protection of your skeletal muscles against fatigue.

operate commercially, meaning that eight have apparently ceased to operate while 25 new companies have emerged during the past 2 years. It was observed that some of the companies listed in box 1 appear to either be linked to each other in some way (perhaps rebranded for different markets or countries/cultures), or linked to local 'clinics' (not included in box 1) via which the genetic tests are marketed. Several of the companies use their clients' genetic test results as opportunities to offer other aspects of their commercial activities for which additional fees are charged, such as training advice and especially nutritional supplements. However, the evidence to support linking specific training advice and nutritional supplements based on genetic data is extremely weak. Of the companies we identified, $54 \%$ of the companies offering DTC genetic tests related to exercise and sport do not publicly state which genetic variants they rely on. While commercial pressures undoubtedly exist, it is impossible for anyone-consumer, academic scholar or others - to scrutinise the service provided by the companies if the detail is not presented to the public. Quite literally millions of genetic tests could theoretically be conducted, so the choice of which variants are tested - and how the results are interpretedis absolutely fundamental to the usefulness of the test. The reasons for such apparent secrecy are presumably commercial sensitivity in part, although it is tempting to conclude that failing to publicise the tests conducted is a tacit admission that the scientific evidence supporting the genetic variants chosen is weak. $^{16} 17$

The UK Human Genetics Commission, which was disbanded in 2012, developed guidelines in relation to marketing of DTC genetic tests. These suggest that the test provider should comply with any legislation or voluntary codes for advertising of medical tests and that they should also comply with more general guidance (including legal guidance) covering consumer advertising. ${ }^{2}$ At a minimum, advertising should:

- Accurately describe both the characteristics and the limitations of the tests offered;

- Not overstate the utility of a genetic test;

- Make sure that any claim made about the clinical validity of a test is supported by relevant evidence published in peer reviewed scientific literature;

- Recognise that the test provider should be aware of the risk of bias when quoting evidence and ensure that evidence is presented.

Furthermore they suggest that the evidence of the association between a genetic marker and a trait should be validated at genome-wide significance level $\left(\mathrm{p}<5 \times 10^{-8}\right)$ in more than one large case-control study and in a cohort of the ethnic/geographic background relevant to the client. This is particularly relevant to talent identification or performance testing where the studies to date are limited in ethnicity and geographic background. In 2008, the Federal Trade Commission (FTC) in the USA issued warnings to consumers that "no standards govern the reliability or quality of at-home genetic tests. The FDA and Centers for Disease Control and Prevention recommend that genetic tests be done in a specialised laboratory and that a doctor or counsellor with specialised training interpret the results." Perhaps it is unsurprising then that the GAO report in 2010 to the US Senate is titled: 'Direct-To-Consumer Genetic Tests-Misleading Test Results Are Further Complicated by Deceptive Marketing and Other Questionable Practices'. ${ }^{15}$

\section{What are the ethical and legal issues around consent and data protection for companies providing this testing?}

There is a consensus in the medical scientific community that genetic tests should be carried out only after the person concerned has given free and informed consent. This can only be provided when a consumer/patient has received sufficient relevant information about the genetic test in such a manner that they are able to understand the risks, benefits, limitations and implications of the genetic test, whose consequences may be indirect and long term. Thus, for example, test data may also have implications in the future for purchase or provision of health or life insurance.

In the UK, the Human Genetics Commission produced guidelines around DTC Genetic Testing services but these had no statutory authority. ${ }^{2}$ It includes clear guidance on consent and includes the following: "Separate, specific, informed consent should be requested by the test provider if the test provider wishes to perform further tests that are not covered by the original consent or if biological samples are to be stored by the test provider after the consumer has been provided with the genetic test results. Likewise, separate informed consent should be requested by the test provider before biological samples are used for any secondary purposes, for example, research, or before any third party is permitted access to biological samples."

In relation to children it offers the following guidance "Genetic tests in respect of children when, according to applicable law, that child does not have capacity to consent should normally be deferred until the attainment of such capacity, unless other factors indicate that testing during childhood is clinically indicated. If postponement would be detrimental to the child's health, or the management of the child's health may be altered significantly depending on the test result, then testing 
should be organised by a health professional who has responsibility for ensuring that any medical intervention or screening indicated will be arranged and proper arrangements made for any subsequent care." These principles of the Human Genetics Commission are applicable to 'lifestyle/behavioural' traits such as performance capacities if they are deemed by to be 'high impact', which is open to debate. For example, if the tests are performed to determine selection and future sporting careers then this may be deemed to have a 'high impact' on the individual-depending on parental or guardian use of the data-but this requires further clarification in the light of specific cases. The American Society for Human Genetics has recently published a position statement that recommends that DTC testing "be discouraged in children until such a time when companies that provide DTC GT can assure quality, accuracy and validity of their testing and assure that there is adequate pretesting and post-testing counselling". ${ }^{18}$

Genetic information is potentially sensitive and as such requires the highest level of security and confidentiality. It is imperative that any personal data and genetic information that are linked to an individual should be subject to privacy protection and security, and cannot be shared without the explicit consent of the individual, in accordance with current professional guidance and applicable laws on data protection and confidentiality. It is also important to consider what should occur if a DTC provider should cease trading or be taken over by a third party.

\section{What are the ethical issues of genetics-based talent identification programmes?}

Genetic information by its very nature means that it is familial. It reveals facts about persons beyond those who have consented to tests, whose results may have direct health implications for other family members. Furthermore the risks of genetic testing for talent identification may not be immediately obvious because the risks may be psychological, social and financial. The psychosocial consequences might include impaired self-esteem, social stigma and, in terms of sport selection, may include employment limitation. The testing may also impact on personal relationships within families or have a life-altering impact on the behaviour of the individual taking the test.

Consumers of the test (coaches, parents, etc) may secure services that they falsely believe will steer children as to which sports most effectively can be pursued according to their genetically derived data. Such predictions are associated with ethical problems that vary according to the individual tested. These range from the narrowing of athletic participation opportunities, a heightening of the dangers of early specialisation, and a failure to engage with what could be activities that provide a lifetime of satisfaction (in the absence of athletic success). These might be thought of as infringements of children's rights to an open future, ${ }^{19-21}$ that parents have a duty to protect. Finally, the use of DTC Genetic Testing is irresponsible when it is provided without genetic counselling. Notably, the UK Human Genetics Commission and the European Society of Human Genetics recommend that genetic tests be provided with appropriate genetic counselling so that test data can be interpreted in the light of the particular individual, their circumstances and the relative predictive power of the test outcomes.

\section{What is the current scientific evidence for genetic testing for talent identification for sport?}

The genetic variants tested most frequently by the companies providing DTC genetic tests related to sport and exercise in 2015 were those in the ACTN3 and ACE genes, which presumably reflects the fact that more research has been conducted on those polymorphisms than any others in the context of sport and exercise. Although the true role of the ACTN3 R577X and ACE I/D variants in skeletal muscle metabolism and strength traits remains controversial, ${ }^{22}$ in meta-analyses the ACE II genotype was associated with physical performance $(\mathrm{OR}=1.23 ; 95 \%$ CI 1.05 to 1.45 ), especially endurance performance (OR 1.35 ; 95\% CI 1.17 to 1.55 ), while ACTN3 RR genotype was associated with speed and power performance $(\mathrm{OR}=1.21 ; 95 \% \mathrm{CI}$ 1.03 to 1.42$).{ }^{23}$ ORs of approximately 1.5 are very small, however and virtually meaningless for talent identification in isolation. For example, while an OR of 1.2 for ACTN3 RR genotype might imply a $20 \%$ greater likelihood of being an elite sprinter than other genotypes, in the UK's $\sim 65$ million population there are an estimated 20 million people of RR genotypebut only a tiny fraction of those people are elite athletes. Indeed, the degree of interindividual variability in sprinting performance that can be explained by ACTN3 genotype, for example, which has been estimated to reach $\sim 2-3 \%,{ }^{24}{ }^{25}$ while based on the broader scientific literature is probably less than $1 \%$. Hence, while there is a little replicated scientific evidence regarding these ACTN3 and ACE polymorphisms on a commercial basis, and one can understand individuals interested in exercise and sport wishing to learn about their own genetic composition within these two well-studied genes, the consensus is that the predictive value of such tests in the context of training responses or talent identification in sport is virtually zero. ${ }^{26}$

There is limited information that can be gleaned from discrete, single marker genetic tests at common polymorphisms. It is totally unwarranted for companies to sell DTC Genetic Testing based on a single variant as there is absolutely no evidence to claim they provide information on which personal exercise training or sport decisions can reasonably be made. Most of the companies identified as offering defined DTC genetic tests assess a panel of multiple genetic variants (median 6 variants, range 1-27). However, when considering genetic variants beyond those that are reasonably well-studied, the level of scientific evidence to support the choice of any particular polymorphism is extremely weak or non-existent. ${ }^{26-28}$ While commercial pressures undoubtedly exist, it would be more responsible to wait for better and stronger scientific evidence before offering genetic tests commercially. Moreover, counselling that puts the genetic information-including the limitations of its usefulness-into proper context is absolutely necessary.

\section{What are the recommendations that can be made from a scientific perspective on the role of DTC in talent identification?}

Based on the published scientific evidence, the information provided by DTC is virtually meaningless for prediction and/or optimisation of sport performance. There is currently no evidence that existing genetic tests provide information that is useful regarding either predisposition for a particular sport, prediction of the training response likely to occur to a particular training programme, or predisposition to exercise-related injury. ${ }^{29}$ It is unknown at this time whether genetic testing, even when knowledge and test validity improves dramatically, will provide information that is not captured within other, traditional non-genetic tests of physiological, anthropometric, medical and performance characteristics that are already used routinely in sport and exercise science and medicine. The key issue is that the question can only be resolved by a comprehensive and highly focused research programme. 


\section{THE CONSENSUS SUMMARY}

The science around genetic testing is an emerging field. With regard to predicting future sporting performance, the scientific foundation is extremely limited and largely non-existent. There is concern among the scientific community that the current level of knowledge is being misrepresented implicitly for commercial purposes. There remains a lack of universally accepted guidelines and legislation for DTC testing in relation to all forms of genetic testing and not just for talent identification. The exercise science and sports medicine community has a duty of care to provide the most up-to-date advice on issues relating to health and well-being of athletes. This also relates to advising sports teams, athletes, parents and children about the absence of scientific evidence and current limitations of genetic testing in predicting future sport performance. There is concern over the lack of clarity of information over which specific genes or variants are being tested and the almost universal lack of appropriate genetic counselling for the interpretation of the genetic data to consumers. Furthermore independent studies have identified issues relating to quality control by DTC laboratories with different results being reported from samples from the same individual. DTC companies must also better address issues around consent, privacy and ownership of data if a company should cease trading or be taken over by a third party.

While further evidence will undoubtedly emerge around the genetics of sport performance in the future, the data are currently very limited. The ACTN3 genotype is the most commonly tested by DTC companies. However, even for this genotype, its contribution to the degree of inter-individual variability in sprinting performance is trivial. Consequently, in the current state of knowledge, no child or young athlete should be exposed to DTC genetic testing to define or alter training or for talent identification aimed at selecting gifted children or adolescents. Large scale collaborative projects, such as the Athlome Project, may help to develop a stronger scientific foundation on these issues in the future but, currently, there is no place for DTC testing for predicting sports performance and talent identification.

An abbreviated consensus statement outlining the key issues and recommendations are available in online supplementary appendix A.

\footnotetext{
Author affiliations

${ }^{1}$ Centre for Sport and Exercise Science and Medicine (SESAME), University of Brighton, Eastbourne, UK

${ }^{2}$ MMU Sports Genomics Laboratory, Department of Exercise and Sport Science, Manchester Metropolitan University, Crewe, UK

${ }^{3}$ College of Engineering, Swansea University, Swansea, UK

${ }^{4}$ Human Genomics Laboratory, Pennington Biomedical Research Center, Baton Rouge, USA

${ }^{5}$ FIMS Reference Collaborating Centre of Sports Medicine for Anti-Doping Research, University of Brighton, Eastbourne, UK

${ }^{6}$ Volga Region State Academy of Physical Culture, Sport and Tourism, Kazan, Russia ${ }^{7}$ Clinical Genomics Service, Center for Inherited Cardiovascular Disease, Stanford University, Palo Alto, California, USA

${ }^{8}$ Faculty of Health Sciences \& Medicine, Bond Institute of Health and Sport, Gold Coast, Australia

${ }^{9}$ Department of Social Science, Health \& Medicine, King's College London, London, UK

${ }^{10}$ Department of Human Biology, University of Cape Town, Cape Town, South Africa

${ }^{11}$ Aspetar-Qatar Orthopaedic \& Sports Medicine Hospital, Doha, Qatar

${ }^{12}$ Institute of Sport, Exercise, and Active Living (ISEAL), Victoria University, Melbourne, Australia

${ }^{13}$ Graduate School of Health and Sports Science, Juntendo University, Tokyo, Japan

${ }^{14}$ Department of Paediatrics, Murdoch Childrens Research Institute, University of Melbourne, Royal Children's Hospital, Victoria, Australia

${ }^{15}$ Coram Chambers, London, UK
}

${ }^{16}$ School of Law, University of Manchester, Manchester, UK

${ }^{17}$ Nuffield Department of Population Health, Centre for Health, Law and Emerging Technologies, University of Oxford, Headington, UK

${ }^{18}$ Emeritus of Ergophysiology, University of Athens, Athens, Greece

${ }^{19}$ Universidad Europea and Research Institute i+12, Madrid, Spain

${ }^{20}$ Elite Sport Unit, Netherlands Olympic Committee * Netherlands Sports

Confederation (NOC*NSF), Utrecht, The Netherlands

${ }^{21}$ Physiological Epigenetics Research Group, University of Stirling, Stirling, UK

${ }^{22}$ International Federation of Sports Medicine, University of Rome, Rome, Italy

Twitter Follow Hendrik Dijkstra at @DrPaulDijkstra and Fleur Garton at @fleurgarton

Acknowledgements The authors would like to thank all the participants of the Genomics Symposium in Santorini who contributed to the debate and agreed to support the consensus statement. These include: Jae Chul Yoo, Sungkyunkwan University School of Medicine, Seoul, Korea. Klaus-Michael Braumann, Abt. Sportund Bewegungsmedizin, Fakultät für Psychologie und Bewegungswissenschaft, Universität Hamburg, Hamburg, Germany. Hans-Hermann Dickhuth, Ehemaliger Ärztlicher Direktor, Abt. Sportmedizin, Freiburg, Germany. Luigi di Luigi, Chief of Department Section of Health Sciences, University of Rome "Foro Italico", Rome, Italy. Norbert Bachl, Department of Sports and Physiological Performance, Centre for Sports Science and University Sports of the University of Vienna, Vienna, Austria. Mohammed Alsayrafi, Anti-Doping Lab Qatar (ADLQ), Doha, Qatar. Mikael Mattsson, Matthew Wheeler-Center for Inherited Cardiovascular Disease, Co-Director Clinical Genomics Service, Stanford University, Stanford, US. Tuomo Rankinen, Mark Sarzinsky-Human Genomics Laboratory, Pennington Biomedical Research Center, Baton Rouge, US. Steven Britton, Lauren Koch-University of Michigan, US. Paul Franks, Department of Clinical Sciences Genetic and Molecular Epidemiology, Lund University, Malmo, Sweden. Eco de Geus, University and VU medical centre, Amsterdam, Netherlands. Valentina Ginevičienè, Vilnius University, Vilnius, Lithuania. Robert Scott, University of Cambridge, Cambridge, UK.

Competing interests None declared.

Patient consent Not obtained.

Provenance and peer review Not commissioned; externally peer reviewed.

Open Access This is an Open Access article distributed in accordance with the Creative Commons Attribution Non Commercial (CC BY-NC 4.0) license, which permits others to distribute, remix, adapt, build upon this work non-commercially, and license their derivative works on different terms, provided the original work is properly cited and the use is non-commercial. See: http://creativecommons.org/ licenses/by-nc/4.0/

\section{REFERENCES}

1 Aymé S, Gribaldo L, Matthijs G, et al. European workshop on genetic testing offer in Europe. Publications Office of the European Union. Ispra, Italy, 2013.

2 Human Genetics Commission. A common framework of principles for direct-to-consumer genetic testing services. London Hum Genet Comm 2010;1-4. http://scholar.google.com/scholar?hl=en\&btnG=Search\&q=intitle:A+Common +Framework+of+Principles+for+direct-to-consumer+genetic+testing+services\#0

3 American College of Medicine Genetics Board of Directors. ACMG statement on direct-to-consumer genetic testing. Genet Med 2004;6:60.

4 Williams AG, Heffernan SM, Day SH. Genetic testing in exercise and sport-have direct-to-consumer genetic tests come of age? Sci Sport Curr Trends 2014;2:3-9.

5 Wetterstrand K. DNA Sequencing Costs: Data from the NHGRI Genome Sequencing Program (GSP). http://www.genome.gov/sequencingcosts (accessed 15 Jul 2015).

6 Su P. Direct-to-consumer genetic testing: a comprehensive view. Yale J Biol Med 2013;86:359-65.

7 Hawkins AK, Ho A. Genetic counseling and the ethical issues around direct to consumer genetic testing. J Genet Couns 2012;21:367-73.

8 Skirton H, Goldsmith L, Jackson L, et al. Direct to consumer genetic testing: a systematic review of position statements, policies and recommendations. Clin Genet 2012:82:210-18.

9 Hauskeller C. Direct to consumer genetic testing. BMJ 2011;342:d2317.

10 Leighton JW, Valverde K, Bernhardt BA. The general public's understanding and perception of direct-to-consumer genetic test results. Public Health Genomics 2011;15:11-21

11 Haddow J, Palomaki G, Khoury M, et al. ACCE: a model process for evaluating data on emerging genetic tests. In: Human genome epidemiology. New York: Oxford University Press, 2004:217-33.

12 Borry $P$, van Hellemondt RE, Sprumont $D$, et al. Legislation on direct-to-consumer genetic testing in seven European countries. Eur J Hum Genet 2012;20:715-21.

13 Wallace H. GeneWatch UK. 2015. http://www.genewatch.org/article.shtml?als[cid] $=396520$ \&als [itemid] $=575612$ (accessed 15 Jul 2015).

14 Institute NHGR. Regulation of Genetic Tests. http://www.genome.gov/10002335 (accessed 15 Jul 2015). 
15 United States Government Accountability Office. DIRECT-TO-CONSUMER GENETIC TESTS. 2010. http://www.gao.gov/assets/130/125079.pdf (accessed 5 Jul 2015).

16 Caulfield T. Predictive or preposterous? The marketing of DTC genetic testing. J Sci Commun 2011. http://jcom.sissa.it/archive/10/03/Jcom1003(2011)C01/Jcom1003 (2011)C02 (accessed 15 Jul 2015).

17 Caulfield T, McGuire AL. Direct-to-consumer genetic testing: perceptions, problems, and policy responses. Annu Rev Med 2012;63:23-33.

18 Botkin JR, Belmont JW, Berg JS, et al. Points to consider: ethical, legal, and psychosocial implications of genetic testing in children and adolescents. Am J Hum Genet 2015;97:6-21.

19 Dixon N. Sport, parental autonomy, and children's right to an open future. J Philos Sport 2007;34:147-59.

20 Feinberg J. A child's right to an open future. In: Aiken W, La Follette H, eds. Whose child? children's rights, parental authority, and state power. Totowa, NJ: Rowman and Littlefield, 1980;124-53.

21 Miah A, Rich E. Genetic tests for ability? talent identification and the value of an open future. Sport Educ Soc 2006;11:259-73.

22 Pérusse L, Rankinen T, Hagberg JM, et al. Advances in exercise, fitness, and performance genomics in 2012. Med Sci Sports Exerc 2013;45:824-31.
23 Ma F, Yang $Y$, Li X, et al. The association of sport performance with ACE and ACTN3 genetic polymorphisms: a systematic review and meta-analysis. PLOS ONE 2013;8:e54685.

24 Moran CN, Yang N, Bailey MES, et al. Association analysis of the ACTN3 R577X polymorphism and complex quantitative body composition and performance phenotypes in adolescent Greeks. Eur J Hum Genet 2007;15:88-93.

25 Ahmetov II, Druzhevskaya AM, Lyubaeva EV, et al. The dependence of preferred competitive racing distance on muscle fibre type composition and ACTN3 genotype in speed skaters. Exp Physiol 2011;96:1302-10.

26 Wang $G$, Padmanabhan S, Wolfarth B, et al. Genomics of elite sporting performance: what little we know and necessary advances. Adv Genet 2013;84:123-49.

27 Bouchard C. Overcoming barriers to progress in exercise genomics. Exerc Sport Sci Rev 2011;39:212-17.

28 Eynon N, Hanson ED, Lucia A, et al. Genes for elite power and sprint performance: ACTN3 leads the way. Sport Med 2013;43:803-17.

29 Hughes DC, Day SH, Ahmetov II, et al. Genetics of muscle strength and power: polygenic profile similarity limits skeletal muscle performance. I Sports Sci 2011;29:1425-34. 